\title{
Diagnóstico do HPV em homens: uma revisão sistemática
}

\author{
Diagnosis of HPV in men: a systematic review \\ Diagnóstico del VPH en hombres: una revisión sistemática
}

Recebido: 31/08/2021 | Revisado: 12/09/2021 | Aceito: 21/09/2021 | Publicado: 23/09/2021

\author{
Andressa Kelly Ferreira e Silva \\ ORCID: https://orcid.org/0000-0002-8606-1407 \\ Universidade Federal do Piauí, Brasil \\ E-mail: andressakelly.fs@gmail.com \\ Maria Luísa Lima Barreto do Nascimento \\ ORCID: https://orcid.org/0000-0002-2242-3392 \\ Universidade Federal do Piauí, Brasil \\ E-mail: mlbarreto95@gmail.com \\ Antonio Luiz Gomes Júnior \\ ORCID: https://orcid.org/0000-0003-0585-3945 \\ Centro Universitário UNINOVAFAPI, Brasil \\ E-mail: gomesjunioral@gmail.com \\ Humberto Medeiros Barreto \\ ORCID: https://orcid.org/0000-0001-5054-7555 \\ Universidade Federal do Piauí, Brasil \\ E-mail: hmbarreto@ufpi.com \\ João Soares da Costa Neto \\ ORCID: https://orcid.org/0000-0002-0406-586X \\ Centro Universitário UniFacid, Brasil \\ E-mail: jsoarescn@gmail.com \\ Maysa Gabriela Costa Cruz \\ ORCID: https://orcid.org/0000-0002-3950-5845 \\ Centro Universitário UNINOVAFAPI, Brasil \\ E-mail: maysagcostac@gmail.com \\ Kairo Igor Freitas de Aquino \\ ORCID: https://orcid.org/0000-0002-7032-3994 \\ Centro Universitário UNINOVAFAPI, Brasil \\ E-mail: kairoigor@hotmail.com \\ Renandro de Carvalho Reis \\ ORCID: https://orcid.org/0000-0002-3194-9767 \\ Centro Universitário UNINOVAFAPI, Brasil \\ E-mail: renandro1981@ hotmail.com
}

\begin{abstract}
Resumo
A infecção pelo papilomavírus humano é a causa de diversas doenças em homens e mulheres. Mais de 100 tipos de HPV são conhecidos e cerca de 30 estão relacionados à infecção anogenital, sendo a infecção viral sexualmente transmissível mais prevalente em todo o mundo. Diante do proposto, o trabalho tem como objetivo realizar uma revisão sistemática sobre o diagnóstico do HPV em homens. O estudo trata-se de uma revisão sistemática com a questão de pesquisa 'como é realizado o diagnóstico do HPV em homens?' Para responder a essa pergunta, foram utilizados os descritores "HPV OR papillomavirus" AND "diagnostic" AND "man OR men", nas bases de dados do PubMed, ScienceDirect e SciELO. Após a extração dos artigos das três bases de dados e aplicação dos critérios de inclusão e exclusão, se chegou ao final com um total de 26 artigos. Dentro da revisão, foram vistos os métodos mais utilizados para a triagem de HPV masculino, como: a peniscopia, avaliação citológica e histológica, ensaios sorológicos, imuno-histoquímica de p16 e os testes moleculares que possuem grande importância no diagnóstico conclusivo, sendo relatados em 14 artigos. O genótipo mais encontrado nos artigos foi o HPV 16, tipo de HPV de alto risco, sendo mencionado em 11 estudos. Além disso, dez enfermidades foram associadas à infecção por HPV como: câncer ou displasia anal, câncer de cabeça e pescoço, câncer peniano, coinfecções com mais de um genótipo de HPV e com vírus de HIV. O estudo foi limitado por falta de padronização metodológica dos artigos utilizados. Embora a prevalência de infecção por HPV em homens seja alta não existe consenso de quais testes devem ser usados para estabelecer um diagnóstico. As diversas metodologias possuem valores de sensibilidade e especificidade diferentes, dessa forma, o diagnóstico da infecção de HPV masculino tende a associar os métodos disponíveis.
\end{abstract}

Palavras-chave: Testes moleculares; Displasia anal; Métodos; Câncer peniano.

\section{Abstract}

Human papillomavirus infection is the cause of several diseases in men and women. More than 100 types of HPV are known and about 30 are related to anogenital infection, with the most prevalent sexually transmitted viral infection 
worldwide. Given the proposal, the work aims to conduct a systematic review on the diagnosis of HPV in men. The study is a systematic review with the research question 'How is HPV diagnosed in men?' To answer this question, the descriptors "HPV OR papillomavirus" AND "diagnostic" and "man OR men" were used, in the PubMed, ScienceDirect and SciELO databases. After extracting the articles from the three databases and applying the inclusion and exclusion criteria, a total of 26 articles was reached at the end. Within the review, the most used methods for screening male HPV were seen, such as: peniscopy, cytological and histological evaluation, serological tests, p16 immunohistochemistry and molecular tests that are of great importance in the conclusive diagnosis, being reported in 14 articles. The genotype most found in the articles was HPV 16, a high-risk type of HPV, being mentioned in 11 studies. In addition, ten diseases were associated with HPV infection such as: cancer or anal dysplasia, head and neck cancer, penile cancer, co-infections with more than one HPV genotype and with HIV virus. This study was limited due to the lack of methodological standardization of the papers used. Although the prevalence of HPV infection in men is high, there is no consensus on which tests should be used to establish a diagnosis. The different methodologies have different sensitivity and specificity values, thus, the diagnosis of male HPV infection tends to associate the available methods.

Keywords: Molecular tests; Anal dysplasia; Methods; Penile cancer.

\begin{abstract}
Resumen
La infección por el virus del papiloma humano es la causa de varias enfermedades en hombres y mujeres. Se conocen más de 100 tipos de VPH y alrededor de 30 están relacionados con la infección anogenital, siendo la infección viral de transmisión sexual más prevalente en todo el mundo. Ante la propuesta, el trabajo tiene como objetivo realizar una revisión sistemática sobre el diagnóstico de VPH en hombres. El estudio es una revisión sistemática con la pregunta de investigación '¿Cómo se diagnostica el VPH en los hombres?' Para responder a esta pregunta, se utilizaron los descriptores "VPH OR papillomavirus" AND "diagnóstico" y "hombre O hombres", en las bases de datos PubMed, ScienceDirect y SciELO. Tras extraer los artículos de las tres bases de datos y aplicar los criterios de inclusión y exclusión, se alcanzó al final un total de 26 artículos. Dentro de la revisión, se observaron los métodos más utilizados para el cribado del VPH masculino, tales como: peniscopia, evaluación citológica e histológica, pruebas serológicas, inmunohistoquímica p16 y pruebas moleculares que son de gran importancia en el diagnóstico concluyente, siendo reportadas en 14 artículos. El genotipo más encontrado en los artículos fue el VPH 16, un tipo de VPH de alto riesgo, mencionado en 11 estudios. Además, diez enfermedades se asociaron a la infección por VPH como: cáncer o displasia anal, cáncer de cabeza y cuello, cáncer de pene, coinfecciones con más de un genotipo de VPH y con el virus del VIH. El estudio fue limitado debido a la falta de estandarización metodológica de los artículos utilizados. Aunque la prevalencia de la infección por VPH en los hombres es alta, no existe consenso sobre qué pruebas deben usarse para establecer un diagnóstico. Las diferentes metodologías tienen diferentes valores de sensibilidad y especificidad, por lo que el diagnóstico de infección por VPH masculina tiende a asociar los métodos disponibles.
\end{abstract}

Palabras clave: Pruebas moleculares; Displasia anal; Métodos; Cáncer de pene.

\title{
1. Introdução
}

A infecção pelo papilomavírus humano é a causa de diversas doenças em homens e mulheres. Mais de 100 tipos de HPV são conhecidos e cerca de 30 estão relacionados à infecção anogenital, sendo a infecção viral sexualmente transmissível mais prevalente em todo o mundo (Freire et al., 2014). Estima-se que a prevalência da infecção por HPV atinja cerca de 630 milhões de pessoas no mundo, onde aproximadamente $80 \%$ da população sexualmente ativa já tenham entrado em contato com o vírus. No Brasil, estima-se que exista 9 a 10 milhões de infectados, onde a cada ano, surjam 700 mil novos casos (Abreu et al., 2018), porém este índice pode ser consideravelmente maior quando é levado em questão a dificuldade de rastreio de forma adequada em algumas regiões do Brasil. Essa realidade se dá em especial pela escassez de conhecimento de algumas mulheres sobre o objetivo e importância do exame, principalmente em regiões mais precárias (Albuquerque et al., 2014; Barreto, 2014).

$\mathrm{O}$ vírus tem um papel etiológico bem definido no condiloma e no câncer de colo de útero, mas também pode caracterizar um fator de risco para o acometimento de outras neoplasias, como o câncer de vagina, vulva, pênis, ânus e nasofaringe (Lima; Lopes; Batista, 2020). De acordo com o potencial oncogênico os tipos virais podem ser classificados com de baixo risco (tipos 6, 11, 42, 43 e 44) e de alto risco (tipos 16, 18, 31, 33, 35, 39, 45, 46, 51, 52, 56,58, 59 e 68). Mundialmente, o HPV 16 e 18 atinge cerca de 105 milhões de pessoas (Fedrizzi et al., 2011).

Na população masculina, a infecção por HPV geralmente apresenta caráter benigno, na forma subclínica da doença. Por outro lado, a forma clínica pode se manifestar por meio do aparecimento de verrugas genitais e desenvolvimento de 
neoplasia intraepitelial peniana, neoplasia intraepitelial anal e o carcinoma invasivo. Entretanto, a evolução, a manifestação dos sintomas e o tratamento ocorrem de forma diferenciada no homem, o que pode ser explicado pelas diferenças anatômicas e hormonais entre os sexos (Vaccarella et al., 2011).

Pesquisas indicam que o homem contribua para a proliferação da doença, sendo um importante agente transmissor. Os indivíduos que foram expostos e infectados pelo HPV, na sua grande maioria, desconhecem que são portadores do vírus, pois geralmente não possuem sinais e sintomas de doenças aparentes (Ministério da Saúde, 2017). Dessa forma, o homem mesmo sem manifestações clínicas visíveis pode transmitir o vírus aos (às) seus (suas) parceiros (as) sexuais, auxiliando indiretamente para o alto número de neoplasias cervicais. Além disso, mesmo que uma menor proporção quando comparado às mulheres, os homens podem apresentar significativa morbidade e mortalidade devido às doenças associadas ao HPV (Feller $e t$ $a l ., 2009)$.

O diagnóstico do HPV pode ser realizado através de exames clínicos e laboratoriais de acordo com o grau da doença e o tipo de lesão. Primeiramente, existe a necessidade da realização de anamnese abordando o histórico do paciente, incluindo informações como: o número de parceiros sexuais, os tipos de práticas sexuais e as doenças sexualmente transmissíveis anteriores (Santos; Maioral; Haas, 2011). Em seguida, deve-se realizar o exame físico, quando existe o aparecimento de sintomas genitais, e exames laboratoriais complementares para a pesquisa direta e indireta do vírus (Rocha et al., 2015).

Dentro dos exames laboratoriais, existem diversas metodologias baseadas na detecção do genoma do HPV nas células humanas como imunofluorescência direta, captura híbrida, a reação em cadeia da polimerase (PCR) e a hibridização in situ (Santos; Maioral; Haas, 2011). Outra forma de diagnóstico é a biópsia que consiste na retirada de pequena amostra de tecido para análise, coleta baseada no aspecto e localização das lesões. O exame histológico avalia o efeito citopático do vírus nas células da epiderme (Solomon; Nayar, 2004).

Diante do alto índice de prevalência da infecção por HPV na população masculina, o trabalho teve por objetivo investigar o diagnóstico do HPV em homens por meio de uma revisão sistemática.

\section{Metodologia}

\section{Estratégia de busca}

O estudo trata-se de uma revisão sistemática (Ercole, Melo e Alcoforado, 2014) por visar responder uma questão de pesquisa, ao qual nesse estudo foi 'como é realizado o diagnóstico do HPV em homens?' Para responder a essa pergunta, foram utilizados os descritores "HPV OR papillomavirus" AND "diagnostic" AND "man OR men", nas bases de dados do PubMed, ScienceDirect e SciELO. Os descritores foram aplicados no sistema de busca avançada para título e resumo, o que tornou a busca mais objetiva.

\section{Critérios de inclusão}

Artigos clínicos longitudinais e transversas com registro de diagnóstico e Short communication foram classificados como elegíveis para a busca. Publicações em qualquer língua foi considerada para o estudo. Dessa maneira, a pergunta de pesquisa pode ser respondida. O recorte temporal de 2016 a 2021 foi utilizado nessa pesquisa.

\section{Critérios de exclusão}

Artigo duplicado foi excluído do resultado da inclusão. Estudo de casos não possuem dados clínicos suficientes, logo, não foram enquadrados. Artigos originais transversais que tivessem abordagem do tipo "relato de experiência" também foram excluídos. Estudos com aplicação de questionário on-line foram descartados devido aos vieses de participação. Essa última modalidade de pesquisa possibilita múltiplas respostas para o mesmo indivíduo e falta de seletividade igualitária dos 
participantes. Artigos que consistiam apenas de um resumo sem qualquer manuscrito publicado, cartas, editoriais, palestras, livros, revisões ou anotações não foram incluídos na amostra final.

\section{Desenho do estudo}

Um modelo fluxograma PRISMA foi adotado para essa seção. A primeira etapa foi a de identificação e busca nas bases de dados. Logo após, na fase de triagem, fora aplicado os critérios de inclusão e exclusão baseado nos tipos de estudo e na leitura dos resumos. A etapa seguinte foi a aplicação dos critérios de elegibilidade após leitura dos textos na íntegra. Dessa forma, foi realizada a inclusão de todos os artigos com pesquisas que objetivassem diagnosticar o HPV em homens. Essa etapa foi conduzida entre os dias 02 e 05 de maio de 2021. Os dados de interesse foram divididos em: Identificação do estudo, tamanho da amostra, média de idade, tipo de estudo, forma de diagnóstico, tipos de HPV e enfermidades associadas.

\section{Resultados e Discussão}

Após a extração dos artigos das três bases de dados e aplicação dos critérios de inclusão e exclusão, se chegou ao final com um total de 26 artigos, que foram completamente lidos e seus dados extraídos. Esse processo de filtragem dos artigos é demonstrado pelo histograma abaixo (Figura 1) e os artigos resultantes caracterizados no quadro a seguir (Quadro 1).

Dos 26 artigos selecionados para a redação do artigo, quatro deles não descreveram qual tipo de estudos eram, dois tipos de estudo tiveram cinco artigos cada, o transversal e o observacional retrospectivo, além desses outros tipos de estudos apareceram na pesquisa, tais como caso controle, observacional prospectivo, coorte retrospectivo, multicêntrico, rastreamento e coorte. A predominância de estudos transversais se dá pela maior facilidade de observar distribuições de incidência ou prevalência de algum fator utilizando o mesmo (Bordalo, 2006) e os estudos observacionais retrospectivos nos permite utilizar dados passados com a finalidade de traçar rotas em comum nas ações tomadas e com isso pode-se tanto evitar cometer erros quanto expor ações que obtiveram sucesso (dos Santos et al., 2019).

Figura 1 - Histograma do processo de extração dos artigos nas bases de dados.

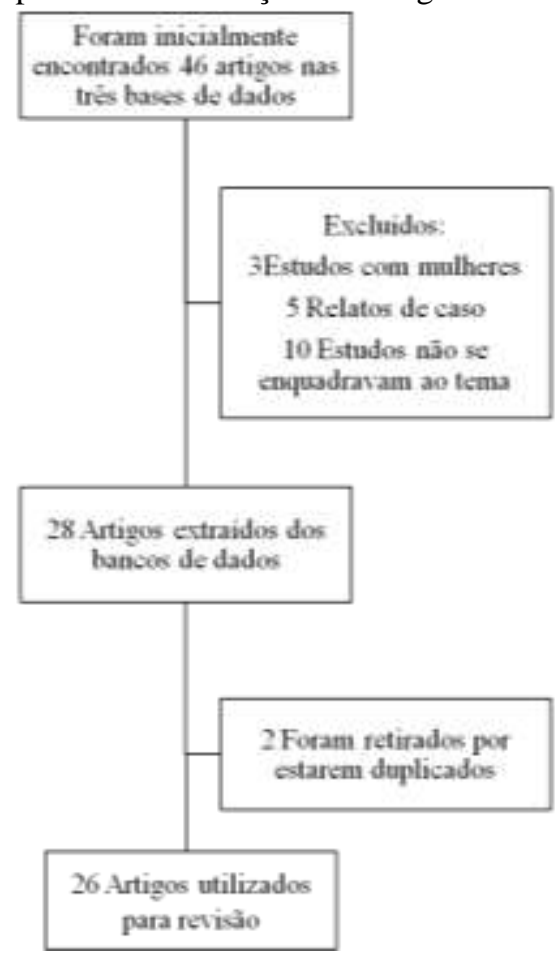

Fonte: Autores. 
O Quadro 1 detalha os principais resultados da extração dos artigos selecionados na busca. Esses dados de interesse englobam o autor, tipo de estudo, tamanho da amostra, idade média, diagnóstico, tipos de HPV diagnosticados e enfermidades associadas ao HPV na população masculina investigada.

Quadro 1 - Síntese qualitativa da busca ativa nas bases de dados.

\begin{tabular}{|c|c|c|c|c|c|c|}
\hline Autor & Tipo de estudo & $\begin{array}{c}\text { Tamanho } \\
\text { da amostra }\end{array}$ & $\begin{array}{l}\text { Idade média } \\
\text { dos pacientes }\end{array}$ & Forma de diagnostico & $\begin{array}{c}\text { Tipos de } \\
\text { HPVs }\end{array}$ & $\begin{array}{c}\text { Enfermidades } \\
\text { associadas }\end{array}$ \\
\hline $\begin{array}{l}\text { Zhu et al., } \\
\qquad 2019\end{array}$ & Prospectivo & 512 & 37 anos & $\begin{array}{c}\text { Baseado na história } \\
\text { epidemiológica e } \\
\text { manifestações clínicas } \\
\text { teste de ácido acético branco } \\
\text { e genotipagem do HPV por } \\
\text { hibridização de ácido } \\
\text { nucleico }\end{array}$ & $\begin{array}{l}\text { HPV } 6,11 \\
52 \text { e } 16\end{array}$ & $\begin{array}{c}\text { Coinfecção do tipo de } \\
\text { HPV em verrugas }\end{array}$ \\
\hline $\begin{array}{l}\text { García- } \\
\text { Muentes et } \\
\text { al., } 2019\end{array}$ & Não informado & $\begin{array}{l}\text { 400: } 253 \\
\text { positivos }\end{array}$ & Entre 18-39 & $\begin{array}{l}\text { Diagnóstico clínico e } \\
\text { genotipagem do HPV }\end{array}$ & $\begin{array}{l}\text { HPV } 6,16 \\
18 \text { e } 11\end{array}$ & $\begin{array}{l}\text { Coinfecção do tipo de } \\
\text { hpv em verrugas }\end{array}$ \\
\hline $\begin{array}{l}\text { Truzzi et al., } \\
2020\end{array}$ & $\begin{array}{l}\text { Estudo } \\
\text { retrospectivo de } \\
\text { coorte }\end{array}$ & $\begin{array}{l}\text { 1132: } 784 \\
\text { positivos }\end{array}$ & $\begin{array}{l}36 \text { anos } \\
(12-81)\end{array}$ & $\begin{array}{l}\text { Genotipagem, peniscopia, } \\
\text { citologia e histopatologia }\end{array}$ & $\begin{array}{l}\text { HPV-6, } \\
\text { HPV-42 e } \\
\text { HPV-16 }\end{array}$ & $\begin{array}{c}\text { Coinfecções } \\
\text { ocorreram em } 429\end{array}$ \\
\hline $\begin{array}{l}\text { Muresu et al., } \\
2020\end{array}$ & $\begin{array}{l}\text { Observacional } \\
\text { retrospectivo }\end{array}$ & 32 & 68 anos & $\begin{array}{l}\text { Detecção e genotipagem do } \\
\text { DNA do HPV por rtPCR }\end{array}$ & $\begin{array}{l}\text { HPV- } 16,56 \\
\quad \text { e } 35\end{array}$ & Câncer de pênis \\
\hline $\begin{array}{c}\text { Ribeiro; } \\
\text { Maleki, } 2021\end{array}$ & Não informado & 209 & Não informado & Imunocoloração de p16 & $\begin{array}{l}\text { HPV } 3,6 \text { e } \\
127\end{array}$ & $\begin{array}{c}\text { Carcinomas de } \\
\text { células escamosas de } \\
\text { cabeça e pescoço }\end{array}$ \\
\hline $\begin{array}{l}\text { Piroozmand } \\
\text { et al., } 2020\end{array}$ & $\begin{array}{c}\text { Estudo } \\
\text { transversal }\end{array}$ & $\begin{array}{l}96 \text { homens } \\
\text { inférteis }\end{array}$ & Não informado & $\begin{array}{c}\text { Análise do sêmen e o teste } \\
\text { diagnóstico de PCR }\end{array}$ & $\begin{array}{l}\text { Não } \\
\text { informado }\end{array}$ & Infertilidade \\
\hline $\begin{array}{l}\text { Lafferre et } \\
\text { al., } 2020\end{array}$ & $\begin{array}{c}\text { Estudo } \\
\text { transversal }\end{array}$ & $\begin{array}{l}60 \text { homens } \\
48 \mathrm{HIV+}\end{array}$ & $\begin{array}{l}\text { Mediana de } \\
37,5 \text { anos }\end{array}$ & Histológico & $\begin{array}{l}\text { Não } \\
\text { informado }\end{array}$ & $\begin{array}{c}\text { Displasia anal, câncer } \\
\text { retal }\end{array}$ \\
\hline $\begin{array}{l}\text { Weiland et } \\
\text { al., } 2020\end{array}$ & $\begin{array}{c}\text { Estudo } \\
\text { multicêntrico }\end{array}$ & $\begin{array}{c}1.486 \\
\text { pacientes }\end{array}$ & Não informado & $\begin{array}{l}\text { Ensaio sorológico específico } \\
\text { do epítopo HPV16-L1 DRH1 } \\
\text { (desenvolvimento de } \\
\text { biomarcador) }\end{array}$ & HPV 16 & $\begin{array}{l}\text { Carcinoma de células } \\
\text { escamosas de cabeça } \\
\text { e pescoço; câncer } \\
\text { anal associado a HIV }\end{array}$ \\
\hline $\begin{array}{c}\text { Donà et al., } \\
2018\end{array}$ & $\begin{array}{c}\text { Estudo } \\
\text { transversal }\end{array}$ & $1021 \mathrm{HSH}$ & 45 anos & $\begin{array}{c}\text { Citologia em meio líquido } \\
\text { genotipagem Linear Array } \\
\text { HPV }\end{array}$ & $\begin{array}{c}\text { HPV-16 e } \\
18\end{array}$ & $\begin{array}{c}\text { Câncer anal } \\
\text { HIV }\end{array}$ \\
\hline
\end{tabular}


Research, Society and Development, v. 10, n. 12, e329101220064, 2021

(CC BY 4.0) | ISSN 2525-3409 | DOI: http://dx.doi.org/10.33448/rsd-v10i12.20064

\begin{tabular}{|c|c|c|c|c|c|c|}
\hline $\begin{array}{c}\text { González- } \\
\text { Hernández et } \\
\text { al., } 2018\end{array}$ & Não informado & 75 & Não informado & $\begin{array}{l}\text { Genotipagem do HPV, duas } \\
\text { abordagens foram } \\
\text { realizadas: Linear Array } \\
\text { HPV Genotyping Test e } \\
\text { next-generation sequencing } \\
\text { (NGS) }\end{array}$ & $\begin{array}{l}\text { HPV6, 62, } \\
61,81,16 \text { e } \\
51\end{array}$ & Câncer anal \\
\hline $\begin{array}{l}\text { Viciana et al., } \\
2019\end{array}$ & $\begin{array}{l}\text { Análise } \\
\text { retrospectiva de } \\
\text { coorte }\end{array}$ & 426 & $\begin{array}{c}40,4 \text { anos }(32,9- \\
48,9)\end{array}$ & $\begin{array}{c}\text { A biópsia guiada por } \\
\text { anuscopia de alta resolução e } \\
\text { citologia anal em base } \\
\text { líquida }\end{array}$ & $\begin{array}{l}\text { Não } \\
\text { informado }\end{array}$ & Câncer retal \\
\hline $\begin{array}{c}\text { Thompson et } \\
\text { al., } 2018\end{array}$ & $\begin{array}{l}\text { Estudo } \\
\text { retrospectivo }\end{array}$ & $\begin{array}{l}314 \text { homens } \\
\text { e mulheres } \\
\text { transexuais }\end{array}$ & $\begin{array}{c}20,4 \operatorname{anos}(13 \mathrm{a} \\
24)\end{array}$ & $\begin{array}{l}\text { Citologia anal } \\
\text { biópsia de tecido anal guiada } \\
\text { por HRA ou intraoperatória. } \\
\text { Coloração de p16 }\end{array}$ & $\begin{array}{l}\text { Não } \\
\text { informado }\end{array}$ & $\begin{array}{c}\text { Displasia e câncer } \\
\text { anal }\end{array}$ \\
\hline $\begin{array}{l}\text { Shaikh et al., } \\
2017\end{array}$ & Não informado & 196 & Não informado & $\begin{array}{l}\text { Sequenciamento automático } \\
\text { de DNA e imuno- } \\
\text { histoquímica com } \\
\text { marcadores p53, Ciclina D1, } \\
\text { pRb e p16 }\end{array}$ & $\begin{array}{l}\text { Não } \\
\text { informado }\end{array}$ & $\begin{array}{c}\text { carcinoma } \\
\text { espinocelular de } \\
\text { cabeça e pescoço }\end{array}$ \\
\hline $\begin{array}{c}\text { Mestrovic et } \\
\text { al., } 2017\end{array}$ & Coorte & 120 & Não informado & $\begin{array}{c}\text { Penoscópica teste do } \\
\text { papilomavírus humano } \\
\text { molecular }\end{array}$ & $\begin{array}{l}\text { Não } \\
\text { informado }\end{array}$ & Não informado \\
\hline $\begin{array}{l}\text { Faneye et al., } \\
2018\end{array}$ & Caso controle & 20 & 33 anos & $\begin{array}{l}\text { Pesquisa de anticorpo } \\
\text { (ELISA) }\end{array}$ & $\begin{array}{l}\text { HPV16 e } \\
18\end{array}$ & Outras ISTs \\
\hline $\begin{array}{l}\text { Loizou et al., } \\
\qquad 2015\end{array}$ & $\begin{array}{l}\text { Observacional } \\
\text { retrospectivo }\end{array}$ & 45 & 57,6 anos & $\begin{array}{l}\text { PCR, imuno-histoquímica } \\
\text { p16 }\end{array}$ & $\begin{array}{l}\text { Alto, baixo } \\
\text { e médio } \\
\text { grau }\end{array}$ & $\begin{array}{c}\text { Câncer de cabeça e } \\
\text { pescoço }\end{array}$ \\
\hline $\begin{array}{l}\text { Profozić et } \\
\text { al., } 2016\end{array}$ & $\begin{array}{l}\text { Observacional } \\
\text { retrospectivo }\end{array}$ & 492 & 41,5 anos & $\begin{array}{c}\text { Técnica de captura hibrida do } \\
\text { DNA }\end{array}$ & $\begin{array}{l}\text { Alto, baixo } \\
\text { e médio } \\
\text { grau }\end{array}$ & $\begin{array}{c}\text { Não observada, } \\
\text { pesquisa específica }\end{array}$ \\
\hline $\begin{array}{l}\text { Cai et al., } \\
2016\end{array}$ & Rastreamento & 105 & 34,8 anos & Quantificação de DNA & $\begin{array}{l}\text { Alto, baixo } \\
\text { e médio } \\
\text { grau }\end{array}$ & Parceira positiva \\
\hline $\begin{array}{c}\text { Nowak et al., } \\
2017\end{array}$ & $\begin{array}{c}\text { Estudo } \\
\text { transversal }\end{array}$ & 94 & Não informado & $\begin{array}{l}\text { Sequenciamento de próxima } \\
\text { geração comparado ao linear } \\
\text { array da roche (melhor, } \\
\text { padrão ouro); prieiro alto } \\
\text { grau anal }\end{array}$ & $\begin{array}{l}\text { Alto, baixo } \\
\text { e médio } \\
\text { grau }\end{array}$ & $\begin{array}{l}\text { Câncer cabeça } \\
\text { pescoço/câncer } \\
\text { cervical }\end{array}$ \\
\hline
\end{tabular}


Research, Society and Development, v. 10, n. 12, e329101220064, 2021

(CC BY 4.0) | ISSN 2525-3409 | DOI: http://dx.doi.org/10.33448/rsd-v10i12.20064

\begin{tabular}{|c|c|c|c|c|c|c|}
\hline $\begin{array}{l}\text { Arana et al., } \\
2015\end{array}$ & $\begin{array}{l}\text { Observacional } \\
\text { retrospectivo }\end{array}$ & 12 & 42,8 anos & Quantificação de DNA & $\begin{array}{l}\text { Não } \\
\text { informado }\end{array}$ & $\begin{array}{c}\text { Câncer de células } \\
\text { escamosas anal (grau } \\
1 \text { e } 2 \text { ) }\end{array}$ \\
\hline $\begin{array}{l}\text { Machalek et } \\
\text { al., } 2016\end{array}$ & coorte & 605 & $\geq 35$ anos & $\begin{array}{l}\text { Histologia e citologia da } \\
\text { biopsia anal }\end{array}$ & Hpv16 & $\begin{array}{l}\text { Lesão intraepitelial } \\
\text { escamosa anal }\end{array}$ \\
\hline $\begin{array}{l}\text { La Vignera et } \\
\text { al., } 2015\end{array}$ & Caso controle & 10 & 32 anos & $\begin{array}{l}\text { Algoritmo de diagnostico; } \\
\text { PRC do semes }\end{array}$ & $\begin{array}{l}\text { Hpv } 16,18 \\
\text { e } 66\end{array}$ & $\begin{array}{l}\text { Infecção da glândula } \\
\text { acessória masculina }\end{array}$ \\
\hline $\begin{array}{c}\text { Sendagorta et } \\
\text { al., } 2015\end{array}$ & $\begin{array}{c}\text { Transversal de } \\
\text { triagem }\end{array}$ & 71 & 40 anos & Ensaio de CLART & Hpv16 & $\begin{array}{l}\text { Lesão intraepitelial } \\
\text { escamosa anal }\end{array}$ \\
\hline $\begin{array}{l}\text { Perruchoud et } \\
\text { al., } 2016\end{array}$ & $\begin{array}{l}\text { Observacional } \\
\text { retrospectivo }\end{array}$ & 9 & 52 anos & PCR & $\begin{array}{l}\text { Hpv } 16,73 \\
\text { e } 52\end{array}$ & $\begin{array}{l}\text { tumores verrucosos } \\
\text { periungueais e } \\
\text { subungueais; doença } \\
\text { e Bowen na unha }\end{array}$ \\
\hline $\begin{array}{l}\text { Ron et al., } \\
2021\end{array}$ & Caso controle & 128 & Não informado & $\begin{array}{c}\text { Sequenciamento de RNA e } \\
\text { biopsia de amostra anal }\end{array}$ & $\begin{array}{l}\text { Não } \\
\text { informado }\end{array}$ & $\begin{array}{l}\text { Neoplasia escamosa } \\
\text { intraepitelial de alto } \\
\text { grau e HIV positivo }\end{array}$ \\
\hline $\begin{array}{c}\text { Pereira; } \\
\text { Lacerda; } \\
\text { Barros, } 2008\end{array}$ & $\begin{array}{l}\text { Observacional } \\
\text { retrospectivo }\end{array}$ & 6 & 38,4 anos & Biopsia de amostra anal & $\begin{array}{l}\text { Não } \\
\text { informado }\end{array}$ & $\begin{array}{l}\text { Lesões de baixo, } \\
\text { médio e alto grau em } \\
\text { pacientes HIV } \\
\text { positivo }\end{array}$ \\
\hline
\end{tabular}

Fonte: Autores.

HPV Papiloma vírus humano. HIV Vírus da imunodeficiência humana. DNA Ácido desoxirribonucleico. RNA Ácido ribonucleico. PCR Reação em cadeia de polimerase. ELISA Enzyme Linked Immuno Sorbent Assay. HSH Homens que fazem sexo com homens

Como já descrito o vírus do papiloma humano é umas das ISTs mais comuns, ela pode ser contraída através do contato entre mucosas ou mucosa e fluidos, como o sêmen. É um vírus com grande variabilidade com mais de cem genotípica, sendo 14 deles de alto risco, com os tipos 16 e 18 mais associados ao desenvolvimento do carcinoma. Por conta dessa maior agressividade dos dois sorotipos, houve o desenvolvimento da vacina contra ambos e promoção de campanhas para a aplicação da mesma, essa ação demonstrou um efeito positivo na prevenção (Fedrizzi et al., 2011; freire et al., 2014; Brianti; de Flammineis; Mercuri, 2017).

Apesar de ser muito bem conhecidos e discutidos, a presença do vírus e seus efeitos nos portadores, a atenção básica é mais voltada para saúde da mulher, ficando mais difuso os sintomas, diagnósticos e preventivos que devem ser tomados pelos homens, que muitas vezes são os principais portadores assintomáticos e com isso aumentar a disseminação da doença (Agras $e t$ al., 2020). 


\section{Perfil dos pacientes}

Incialmente, o perfil dos pacientes está relacionado aos mais propensos e que recorrem a pesquisa do HPV. No total, obteve-se uma população de 8.666 homens, sendo que 6.313 positivos para HPV (Figura 2) foi observada um grande intervalo das idades, indo de 12 a 81, com uma média de 39,9 anos. Apesar disso, oito estudos não trouxeram a idade dos pacientes.

Figura 2 - Distribuição da população.

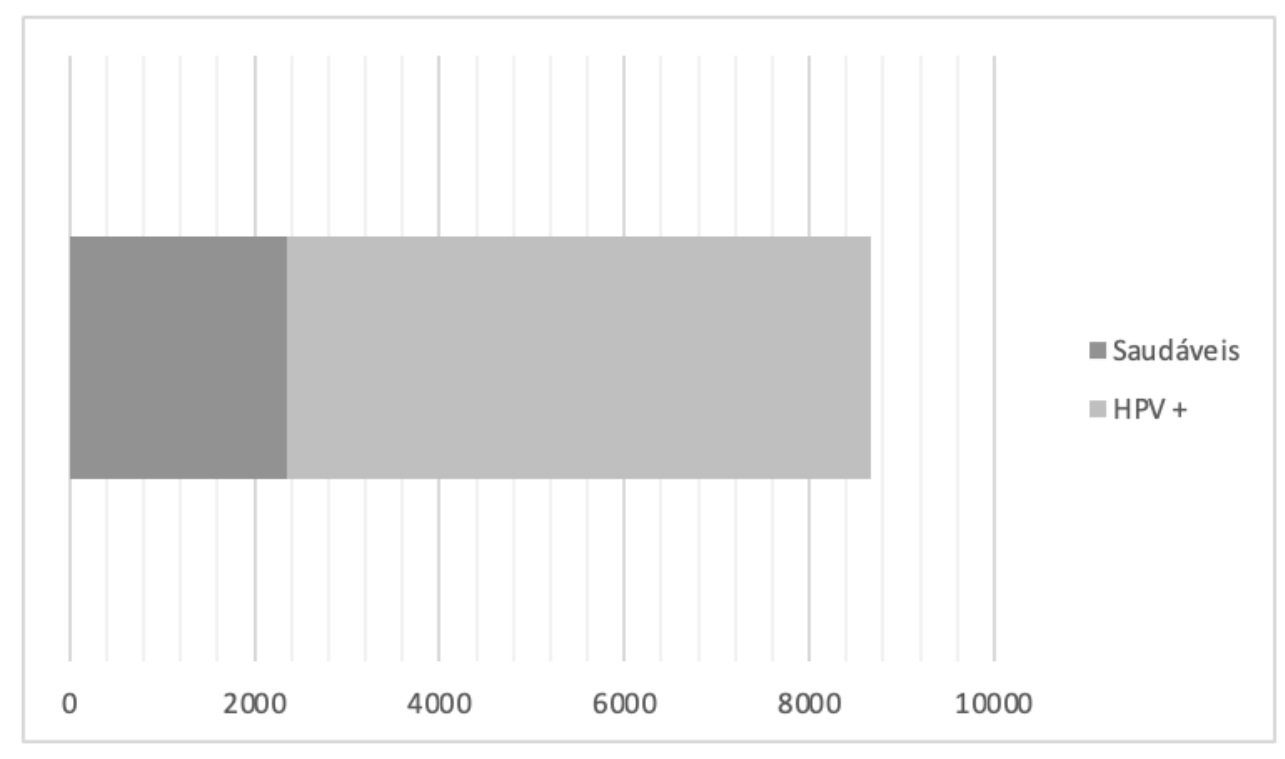

Fonte: Autores.

Não houve uma descrição específica de status ou orientação sexual, em que apenas dois estudos trouxeram tal informação, Faneye et al (2018) que demonstrou uma homogeneidade entre pacientes casados e solteiros e Machalek et al (2016) relatou uma maior incidência de casos em homens homossexuais.

\section{Formas de Diagnóstico}

Embora a prevalência de infecção por HPV em homens seja alta, chegando a uma taxa de até $65 \%$, não existe consenso de quais testes devem ser usados para estabelecer um diagnóstico de infecção por HPV em homens (Truzzi et al., 2020). Dentro da revisão, foram vistos os métodos mais utilizados para a triagem de HPV masculino, como: a peniscopia, avaliação citológica e histológica, ensaios sorológicos, imuno-histoquímica de p16. Além dos testes moleculares como: PCR (Reação em cadeia da polimerase) em tempo real e a hibridização. As diversas metodologias possuem valores de sensibilidade e especificidade diferentes, dessa forma, o diagnóstico da infecção de HPV masculino tende a associar os ensaios disponíveis (Burd, 2016).

No estudo de ZHU e colaboradores (2019), utilizou-se critérios de diagnóstico de verrugas genitais baseada no histórico epidemiológico do paciente e manifestações clínicas. Tais manifestações clínicas são descritas como lesões papulóides ou massas papilares, coronais que se assemelham a couve-flor. Também investigando lesões cutâneas atípicas fazendo o uso do ácido acético. De forma similar, o método de peniscopia utiliza o ácido acético 5\% nas regiões do pênis e do escroto, em seguida, toda a área genital é examinada examinado sob ampliação óptica de 10 a 16 vezes, o resultado do exame mostra lesões acetobrancas (Truzzi et al., 2020). A penoscopia é uma técnica relevante, mas não uma ferramenta diagnóstica conclusiva para diferenciar achados de HPV de não HPV em homens, sendo necessária a associação de testes de DNA viral (Mestrovic et al., 2017). 
O diagnóstico citológico é mais comumente utilizado para avaliar lesões associadas ao HPV na região anal. No estudo de Viciana et al (2019), a citologia em meio líquido foi usada para avaliar as lesões citológicas anais em indivíduos com risco aumentado de câncer anal. A técnica consiste em rotacionar um swab no canal anal, em seguida agitá-lo no meio líquido para que as células se desprendam. São confeccionadas as lâminas citológicas e seus resultados são classificados de acordo com as Diretrizes da Bethesda, que também foram aceitas para citologia anal (Dona et al., 2018).

A avaliação histológica se mostrou presente na investigação das diversas enfermidades associadas à infecção por HPV. A metodologia foi utilizada para avaliar verrugas e lesões no pênis (Truzzi et al., 2020) como também lesões anais atípicas. O protocolo seguido produzia cortes de 5 mícrons retirados das amostras fixadas em formalina e embebidas em parafina e, em seguida, coradas com hematoxilina e eosina (Thompson et al., 2018). O estudo de Ron et al (2021) dá destaque à biópsia guiada por anuscopia de alta resolução, que hoje é considerada o padrão ouro para a detecção de HSILs e câncer anal, tal método utiliza como aparato um anoscópio e uma câmera de alta resolução.

Dentro desse contexto, os cortes histológicos podem passar pelo processo de imunocoloração. A metodologia de imuno-histoquímica de proteína 16 é utilizada no diagnóstico, principalmente, de carcinomas de células escamosas de cabeça e pescoço relacionados ao HPV (Ribeiro; Maleki, 2020). A p16 é um gene supressor de tumor no mecanismo de controle do ciclo celular e está presente nas células normais em níveis baixos. Entretanto, a atividade transformadora do oncogene E7, presente em tipos de HPV de alto risco, proporciona uma forte superexpressão de p16 nas células displásicas sendo facilmente mostrado no método (Dogantemur et al., 2020).

Os ensaios moleculares possuem grande importância no diagnóstico conclusivo, realizando a detecção e genotipagem do DNA viral, sendo relatados na maioria dos estudos desta revisão, precisamente 14 artigos. O PCR em tempo real promove a detecção concomitante à amplificação do genoma do vírus. A partir do produto do PCR é realizada a hibridização de ácido nucleico responsável por identificar os tipos de HPV (Loizou et al., 2015; Shaikh et al., 2017; Zhu et al., 2019). Exemplo disso, o estudo de Muentes et al (2019) fez uso das técnicas de biologia molecular para determinar a frequência e distribuição dos genótipos de HPV de amostras de lesões genitais.

\section{Genótipos de HPV}

Dentro da revisão, percebemos que o genótipo mais encontrado nos artigos foi o HPV 16, tipo de HPV de alto risco, sendo mencionado em 11 estudos. Seguido por o HPV 18, também classificado como alto risco, mencionado em 4 trabalhos. Com o mesmo número de trabalhos, o HPV 6 é um dos genótipos mais comuns e é classificado como de baixo risco. Por fim, o HPV 11 e HPV 52, ambos com 3 menções, são classificados como baixo e alto risco, respectivamente (Figura 3). 
Figura 3 - Frequência dos cinco genótipos Carlos Henrique Pereira damais encontrados.

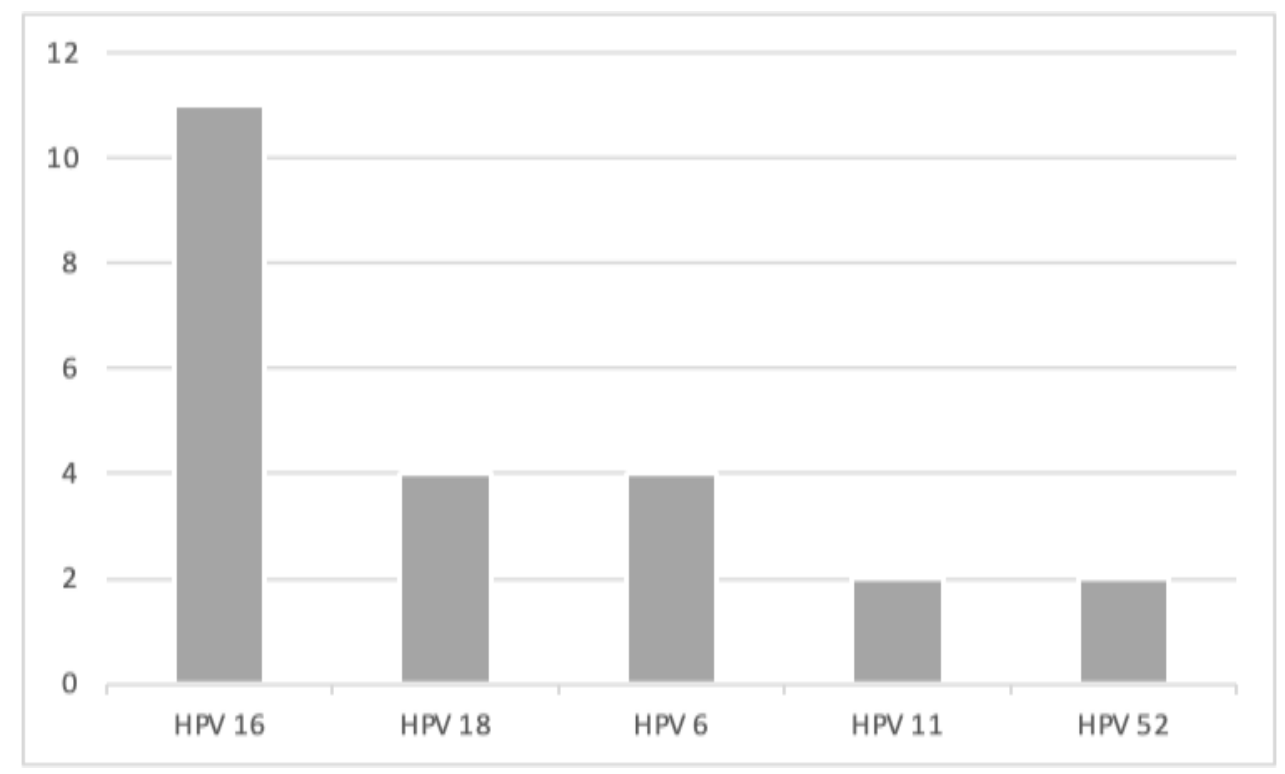

Fonte: Autores.

É consenso que o HPV 16 é o tipo mais frequente globalmente, contudo a contribuição relativa aumenta à medida que o grau da lesão associada é mais alto. Os genótipos HPV 16/18 são responsáveis por 70\% dos casos de câncer cervical invasor (CCI) no mundo (Oliveira et al., 2013; Bruno et al., 2014). Esses dados da população também corroboram com os dados encontrados em nossa revisão da afecção na população masculina.

\section{Doenças associadas}

O último ponto abordado são as doenças associada, as quais muitas vezes levam à procura médica e com isso a um diagnóstico de HPV, exceto o estudo de Mestrovic et al (2017) que não observou essa associação. Dez enfermidades foram associadas a isso, em especial o aparecimento de câncer ou displasia anal foi observado em nove estudos, muitos associam a displasia de alto grau causada pelo vírus com o desenvolvimento do câncer anal, com isso a identificação precoce desta displasia pode impedir que haja um agravamento (Sendagorta et al., 2015; Machalek et al., 2016; Dona et al., 2018; Lafferre et al., 2020), Anara et al (2015) trouxe ainda que, juntamente com a lesão por HPV, a invasão linfo-vascular também está associada ao desenvolvimento do câncer.

González et al (2018) e Thompson et al (2018) ainda observou que a coinfecção de HIV com HPV seja um fator de risco ainda maior para desenvolvimento dessa neoplasia. Dois estudos demonstraram a influência do câncer anal no diagnostico, em que Viciana et al (2019) avaliou cenários que podem ser utilizadas a anoscopia de alta resolução para fins de diagnóstico, enquanto Weiland et al (2020) apresentou o teste de DRH1 como um ensaio inovador para detecção do HPV em homens por apresentar uma especificidade de $90 \%$.

Outro câncer muito associado ao HPV é o de cabeça e pescoço adquirido, principalmente com o contato de fluidos ou com a verrugas na mucosa oral, nos cinco artigos a busca medica decorrente da anomalia leva a descoberta da infecção pelo HPV durando o processo de triagem, diferindo de um artigo para o outro pela técnica de diagnóstico utilizada: imunohistoquímica com p16 (Loizou et al., 2015; Ribeiro; Maleki, 2020), DRH1 com especificidade de 95\% para homens (Weiland et al., 2020), detecção do DNA viral na biopsia (Shaikh et al., 2018) e sequenciamento de próxima geração testado por Nowak et al (2017), apesar do padrão outro ser linear array.

Demais doenças também levaram à pesquisa da etiologia que se mostrou ser pelo HPV, como o câncer cervical 
(Nowak et al, 2017), câncer peniano (Ribeiro; Maleki, 2020), infecção na glândula acessório (La Vignera et al., 2015) e outras infecções associadas, como por exemplo coinfecções com mais de um genótipo de HPV (Zhu et al., 2019; Muentes et al., 2019; Truzzi et al., 2020), com vírus de HIV (Pereira; Lacerda; Barros, 2008; Dona et al., 2018; Ron et al., 2021) ou com outras IST (Fanee et al., 2018). Além dessas, outra complicação que levava o paciente a fazer a pesquisa pelo vírus, era a presença de infertilidade masculina, possivelmente pelo aumento dos anticorpos anti-espermatozóides (Piroozamand et al., 2020).

\section{Conclusão}

Dentro da revisão, foram vistos os métodos mais utilizados para a triagem de HPV masculino, como: a peniscopia, avaliação citológica e histológica, ensaios sorológicos, imuno-histoquímica de p16. Além dos testes moleculares, PCR e hibridização, que possuem grande importância no diagnóstico conclusivo, sendo relatados em 14 artigos. O genótipo mais encontrado nos artigos foi o HPV 16, tipo de HPV de alto risco, sendo mencionado em 11 estudos. Dez enfermidades foram associadas à infecção por HPV, em especial o aparecimento de câncer ou displasia anal foi observado em nove estudos. Outras neoplasias também estão associadas ao vírus como: câncer de cabeça e pescoço, câncer cervical, câncer peniano. Além de outras infecções: coinfecções com mais de um genótipo de HPV e com vírus de HIV. Embora a prevalência de infecção por HPV em homens seja alta não existe consenso de quais testes devem ser usados para estabelecer um diagnóstico de infecção por HPV em homens. Dessa forma, o diagnóstico da infecção de HPV masculino tende a associar os ensaios disponíveis. Apesar da limitação do estudo pelo número de artigos analisados, pode-se verificar que existem métodos para detecção de HPV em homens da mesma forma que existem para as mulheres, porém, a falta de consenso sobre quais métodos devem ser utilizados demonstra a necessidade de mais estudos futuros para se estabelecer um protocolo de rastreio assim como já existe para as mulheres com as diretrizes brasileiras para o rastreamento do câncer do colo do útero.

\section{Referências}

Abreu, M. N. S., Soares, A. D., Ramos, D. A. O., Soares, F. V., Nunes, G., Valadão, A. F., \& Motta, P. G. D. (2018). Conhecimento e percepção sobre o HPV na população com mais de 18 anos da cidade de Ipatinga, MG, Brasil. Ciência \& Saúde Coletiva, 23, 849-860.

Albuquerque, C. L. F. D., Costa, M. D. P., Nunes, F. M., Freitas, R. W. J. F. D., Azevedo, P. R. M. D., Fernandes, J. V., ... \& Barreto, H. M. (2014). Conhecimentos, atitudes e práticas em relação ao exame de Papanicolaou em mulheres no Nordeste do Brasil. São Paulo Medical Journal, 132, 3-9.

Arana, R., Fléjou, J. F., Si - Mohamed, A., Bauer, P., \& Etienney, I. (2015). Características clínico-patológicas e virológicas do carcinoma epidermóide superficialmente invasivo do ânus. Doença colorretal, 17 (11), 965-972.

Barreto H. M., Fernandes J. V., Oliveira; C. R. N. Baixo índice dos conhecimentos sobre o rastreio do (Bajo índice de los conocimientos sobre la detección del) câncer cervical en el norte de Brasil. Salud i Ciencia 21(2):194-6, May 2015.

Brotherton, J. M., Giuliano, A. R., Markowitz, L. E., Dunne, E. F., \& Ogilvie, G. S. (2016). Monitoramento do impacto da vacina contra HPV em homens considerações e desafios. Papillomavirus Research,2, 106-111.Burd, EM (2016). Teste de laboratório do papilomavírus humano: a mudança de paradigma. Revisões de microbiologia clínica, 29 (2), 291-319.

Bruno, A., Serravalle, K., Travassos, A. G., \& Lima, B. G. D. C. (2014). Distribuição dos genótipos de papilomavírus humano em mulheres do estado da Bahia, Brasil. Revista Brasileira de Ginecologia e Obstetrícia, 36, 416-422.

Cai, T., Perletti, G., Meacci, F., Magri, V., Verze, P., Palmieri, A., ... \& Bartoletti, R. (2016). História natural da infecção pelo papilomavírus humano em jovens do sexo masculino não vacinados: baixa probabilidade de eliminação em genótipos de alto risco. European Journal of Clinical Microbiology \& Infectious Diseases, 35 (3), 463-469.

Dogantemur, S., Ozdemir, S., Uguz, A., Surmelioglu, O., Dagkiran, M., Tarkan, O., \& Tuncer, U. (2020). Avaliação da expressão de HPV 16, HPV 18, p16 em pacientes com câncer de laringe em estágio avançado e significância prognóstica. Revista Brasileira de Otorrinolaringologia, 86, $351-357$.

Donà, MG, Benevolo, M., Latini, A., Rollo, F., Colafigli, M., Frasca, M., ... \& Giuliani, M. (2018). Lesões citológicas anais e infecção por HPV em indivíduos com risco aumentado de câncer anal. Cancer cytopathology, 126 (7), 461-470.

Ercole, F. F., Melo, L. S. D., \& Alcoforado, C. L. G. C. (2014). Revisão integrativa versus revisão sistemática. Revista Mineira de Enfermagem, $18(1)$, 9-12.

Faneye, A. O., Adeiga, A. A., Awoderu, O. B., \& Fayemiwo, A. S. (2018). Conscientização da vacina contra o vírus do papiloma humano e histórico de vacinação em pacientes atendidos em clínicas de DST em Lagos e Ibadan, Nigéria. Arquivos de medicina básica e aplicada, 6 (1), 95. 
Fedrizzi, E. N. (2011). Epidemiologia da infecção genital pelo HPV. Rev Bras Pat Trato Gen Inf, 1(1), 3-8.

Feller, L., Khammissa, R. A., Wood, N. H., \& Lemmer, J. (2009). Maturação epitelial e biologia molecular do HPV oral. Agentes infecciosos e câncer, 4 (1), $1-9$.

Freire, M. P., Pires, D., Forjaz, R., Sato, S., Cotrim, I., Stiepcich, M., ... \& Truzzi, JC (2014). Prevalência genital de tipos de HPV e coinfecção em homens. International braz j urol, 40, 67-71.

García-Muentes, G. D., Mendoza-García, M. A., Burgos-Galárraga, R. I., Ollague, K., Vargas-Wachter, C., \& Ruiz-Cabezas, J. C. (2019). Frequência e distribuição dos genótipos do HPV em 800 amostras genitais de homens e mulheres equatorianos da cidade de Guayaquil. Revista do Instituto de Medicina Tropical de São Paulo, 61.

González-Hernández, L. A., Flores-Miramontes, M. G., Aguilar-Lemarroy, A., Quintanilla-Peña, K. S., Martin-Amaya-Barajas, F. L., Ramos-Solano, M., ... \& Jave-Suárez, L. F. (2018). Genótipos de HPV detectados por array linear e sequenciamento de última geração em amostras anais de homens HIV positivos que fazem sexo com homens no México. Arquivos de virologia, 163 (4), 925-935.

La Vignera, S., Vicari, E., Condorelli, R. A., Franchina, C., Scalia, G., Morgia, G., ... \& Calogero, A. E. (2015). Prevalência de infecção pelo vírus do papiloma humano em pacientes com infecção da glândula acessória masculina. Reproductive biomedicine online, 30 (4), $385-391$.

Lafferre, E., Abramowitz, L., Walker, F., Benabderrhamanne, D., Laurain, A., Duval, X., \& Tubach, F. (2020). Displasia anal em pacientes com múltiplas lesões anais de HPV: mosaico ou homogeneidade?. Jornal da Sociedade Coreana de Coloproctologia.

Lima, EL, Lopes, K. C. e Batista, N. J. C. (2020). Fatores que influenciam na manifestação do HPV em homens. Research, Society and Development, 9 (7), e722974817-e722974817.

Loizou, C., Laurell, G., Lindquist, D., Öfverman, C., Stefansson, K., Nylander, K., \& Olofsson, K. (2015). Incidência de câncer tonsilar no norte da Suécia: Impacto do vírus do papiloma humano. Oncology letters, 10 (6), 3565-3572.

Machalek, D. A., Poynten, I. M., Jin, F., Hillman, R. J., Templeton, D. J., Law, C., ... \& Grulich, A. E. (2016). Um ponto final de citologia-histologia composta permite uma estimativa mais precisa da prevalência de lesão intraepitelial escamosa de alto grau anal. Cancer Epidemiology and Prevention Biomarkers, 25 (7), 1134-1143.

Markowitz, L. E., Dunne, E. F., Saraiya, M., Chesson, H. W., Curtis, C. R., Gee, J., ... \& Unger, E. R. (2014). Vacinação contra o papilomavírus humano: recomendações do Comitê Consultivo em Práticas de Imunização (ACIP). Relatório Semanal de Morbidez $e$ Mortalidade: Recomendações $e$ Relatórios, 63 (5), 1-30.

Mestrovic, T., Profozic, Z., Neuberg, M., Kozina, G., Savic, I., \& Profozic, V. (2017). Características e distribuição de lesões penianas em homens croatas com infecção confirmada em laboratório pelo papilomavírus humano (HPV) de baixo e alto risco. Laboratório clínico, 63 (5), $971-981$.

Ministério da Saúde. Guia práticas sobre hpvHPV perguntas e respostas. 2017

Muresu, N., Sotgiu, G., Saderi, L., Sechi, I., Cossu, A., Marras, V., ... \& Piana, A. (2020). Estudo observacional italiano sobre a infecção por HPV, expressão de E6 e p16 em homens com câncer de pênis. Virology Journal, 17 (1), 1-6.

Nowak, R. G., Ambulos, N. P., Schumaker, L. M., Mathias, T. J., White, R. A., Troyer, J., ... \& Cullen, K. J. (2017). Genotipagem de papilomavírus humano anal de alto risco (HPV): sequenciamento de próxima geração de torrente de íons vs. array linear. Virology journal, 14 (1), 1-5.

Oliveira, G. R. D., Vieira, V. C., Barral, M. F. M., Döwich, V., Soares, M. A., Conçalves, C. V., \& Martinez, A. M. B. D. (2013). Fatores de risco e prevalência da infecção pelo HPV em pacientes de Unidades Básicas de Saúde e de um Hospital Universitário do Sul do Brasil. Revista Brasileira de Ginecologia e Obstetrícia, 35, 226-232.

Pereira, A. C. C., Lacerda, H. R. D., \& Barros, R. C. D. R. (2008). Diagnostic methods for prevention of anal cancer and characteristics of anal lesions caused by HPV in men with HIV/AIDS. Brazilian Journal of Infectious Diseases, 12, 293-299.

Perruchoud, D. L., Varonier, C., Haneke, E., Hunger, R. E., Beltraminelli, H., Borradori, L., \& Ehnis Pérez, A. (2016). Bowen disease of the nail unit: a retrospective study of 12 cases and their association with human papillomaviruses. Journal of the European Academy of Dermatology and Venereology, 30(9), 1503-1506.

Piroozmand, A., Nasab, S. D. M., Erami, M., Hashemi, S. M. A., Khodabakhsh, E., Ahmadi, N., \& Vahedpoor, Z. (2020). Distribuição do papilomavírus humano e anticorpo anti-esperma no sêmen e sua associação com os parâmetros do sêmen entre homens inférteis. Jornal de reprodução e infertilidade, 21 (3), 183.

Profozić, Z., Meštrović, T., Savić, I., \& Profozić, V. (2016). Prevalência de infecção por HPV em homens croatas durante um período de 12 anos: um estudo comparativo de esfregaços genitais externos e uretrais. Jornal da Europa Central de Saúde Pública, 24 (4), $321-325$.

Ribeiro, EA, \& Maleki, Z. (2021). Imunocoloração de p16 em espécimes citológicos: sua aplicação, expressão, interpretação e desafios. Journal of the American Society of Cytopathology, 10 (4), 414-422.

Ron, R., Cabello, A., Gosalbes, M. J., Sánchez-Conde, M., Talavera-Rodríguez, A., Zamora, J., ... \& Serrano-Villar, S. (2021). Explorando a microbiota para o diagnóstico de lesões anais pré-cancerosas em homens que fazem sexo com homens. The Journal of Infectious Diseases.

Santos, I. M., Maioral, M. F., \& Haas, P. (2011). Infecção por HPV em homens: Importância na transmissão, tratamento e prevenção do vírus. Estudos de Biologia, 32(76/81). 
Research, Society and Development, v. 10, n. 12, e329101220064, 2021

(CC BY 4.0) | ISSN 2525-3409 | DOI: http://dx.doi.org/10.33448/rsd-v10i12.20064

Sendagorta, E., Romero, M. P., Bernardino, J. I., Beato, M. J., Alvarez - Gallego, M., \& Herranz, P. (2015). Teste de mRNA do papilomavírus humano para a detecção de lesões intraepiteliais escamosas anais de alto grau em homens que fazem sexo com homens infectados pelo HIV. Journal of medical virology, 87 (8), 1397-1403.

Shaikh, M. H., Khan, A. I., Sadat, A., Chowdhury, A. H., Jinnah, S. A., Gopalan, V., ... \& Johnson, N. W. (2017). Prevalência e tipos de papilomavírus humano de alto risco em cânceres de cabeça e pescoço em Bangladesh. Câncer BMC, 17 (1), 1-11.

Solomon, D., \& Nayar, R. (2004). Sistema Bethesda para citopatologia cervicovaginal: Definições, critérios e Notas Explicativas. $2^{\mathrm{a}}$ edição. Editora Revinter Ltda, Rio de Janeiro.

Thompson, A. B., Gillespie, S. E., Mosunjac, M. B., Hussen, S. A., Flowers, L. C. e Camacho-Gonzalez, A. F. (2018). Prevalência de lesões intraepiteliais escamosas anais em homens jovens que fazem sexo com homens e mulheres trans infectados com HIV-1. Journal of lower genital tract disease, 22 (4), 340.

Truzzi, J. C., da Silva, I. D., Freire, M. P., Neto, M. J., Rodrigues, F. F., Maciel, G. A., ... \& Reis, L. O. (2020). Genotipagem contemporânea do papilomavírus humano e correlações com peniscopia, citologia e histopatologia em mais de 1000 homens. Diagnostic cytopathology, 48 (11), 1021-1026.

Vaccarella, S., Plummer, M., Franceschi, S., Gravitt, P., Papenfuss, M., Smith, D., ... \& Giuliano, A. R. (2011). Agrupamento de tipos de papilomavírus humano (HPV) no trato genital masculino: o estudo de HPV em homens (HIM). Journal of Infectious Diseases, 204 (10), 1500-1504.

Viciana, P., Milanés-Guisado, Y., Fontillón, M., Domínguez Castaño, A., Sotomayor, C., Espinosa, N., ... \& Neukam, K. (2019). O teste de alto risco do vírus do papiloma humano melhora o desempenho diagnóstico para predizer neoplasia intraepitelial anal de grau moderado a alto em homens que fazem sexo com homens infectados pelo vírus da imunodeficiência humana em anormalidades citológicas baixas ou ausentes. Clinical Infectious Diseases, 69 (12), 2185 -2192.

Weiland, T., Eckert, A., Tomazic, P. V, Wolf, A., Pondorfer, P., Vasicek, S., ... \& Thurnher, D. (2020). DRH1 - um novo marcador de tumor de HPV baseado no sangue. EBioMedicine, 56, 102804 .

Zhu, C., Wang, Y., Mao, W., Zhang, H., \& Ma, J. (2019). Prevalência e distribuição de tipos de HPV em verrugas genitais em Xi'an, China: um estudo prospectivo. BMJ aberto, 9 (5), e023897. 